\title{
Design and Evaluation of an Online Social Support Application for Family Caregivers
}

\author{
Matthieu Tixier and Myriam Lewkowicz \\ Université de Technologie de Troyes - ICD/ Tech-CICO - UMR CNRS 6279 \\ 12, rue Marie Curie, BP 2060, 10010 Troyes, France \\ \{Matthieu.Tixier, Myriam. Lewkowicz\} @utt.fr
}

\begin{abstract}
A lot of people who live with a loss of autonomy related to ageing or disease benefit from the daily support of some of their relatives in order to perform their day-to-day duties (waking up in the morning, shopping, cooking). Family caregivers are strongly committed to the support relationship with their ailing relative. The assistance they provide takes up a large part of their time and energy. Offering them places for social support appears as a relevant solution. Besides, more and more people are turning towards the Internet to find support when they experience difficult situations. Our research deals with the complex issue of providing online social support to family caregivers through an interdisciplinary research project which aims at getting a better understanding of peer-to-peer social support practices. The healthcare network RéGéMA is our first partner in the requirements analysis, test and deployment of our application, Aloa-aidants.fr.
\end{abstract}

Keywords: Family Caregivers, Social Support, Healthcare Network, Support Group, Interdisciplinary Design.

\section{Introduction}

A lot of people who live with a loss of autonomy related to ageing or disease benefit from the daily support of some of their relatives in order to perform their day-to-day duties (for instance, waking up the morning, shopping, cooking, getting dressed up). The care these family caregivers are providing to their ailing relative is then essential. The French society just starts to become aware of the burden of the family caregivers and solutions are needed to help them. Allowing these caregivers to share their experience and to find a sympathetic hearing to their problems, in other words offering them places for social support, appears as a relevant solution in this context.

Social support constitutes a relevant answer to the moral distress expressed by family caregivers [1]. Barnes and Duck [2] define social support as an exchange of verbal or non-verbal messages, which convey emotion or information, in order to reduce the stress or the uncertainty of a person. This support is traditionally provided by family and friends. It is performed through the exchange of information, advices, emotions or more tangible resources which lend to recognize the value of the person in need of support [9]. 
However, as people today are often living and working far from their family, more and more people are searching for other ways to find support when they experience difficult situations. They are for instance turning towards the Internet to reach and talk with people who are or were going through the same troubles and find a sympathetic hearing to share their problems. Several research work have highlighted these mediated peer-to-peer social support practices and described existing online communities, as empathic communities [3] [5], Virtual Healthcare Communities [4] and patients' online communities as "communities of unintended interest" [11]. Developing such online social support space intended to family caregivers was the aim of our design project in the framework of our partner, the RéGéMA healthcare network.

Our research deals with this complex issue of providing online social support to family caregivers through an action research project which aims at getting a better understanding of peer-to-peer social support practices. In the framework of this project [6] [7], we have worked in cooperation with researchers from Psychology, Sociology and Conversational Analysis in order to inform the design of an online application dedicated to social support. The healthcare network RéGéMA is our first partner in the requirements analysis, test and deployment of the application. This network provides support to patients suffering from memory disorders, like Alzheimer's disease, and their family caregivers in the Aube region (North-East of France).

This paper presents the approach that we have followed in order to design Aloaaidants.fr, an application dedicated to online social support for family caregivers. In what follows, we first describe in more detail the situation of family caregivers and our partner RéGéMA. Opportunities offered by online social support in this context are highlighted. Secondly, we consider the studies carried out within our interdisciplinary project with the aim to guide designers in developing online services usable by family caregivers and relevant for social support practices. Several results that have been of interest for the design of Aloa-aidants.fr are highlighted in this section. Then, we present the technical translation approach we have elaborated in order to design the functionalities of our application on the basis of the results of the studies formerly introduced. We furthermore illustrate our approach by presenting several functionalities intended to develop a social support activity among family caregivers through our application. A first version of Aloa-aidants.fr is now online and we present the results of the first evaluations that we have conducted with RéGéMA family caregivers as well as with another association interested by the use of our system. Finally, we conclude and address some future research perspectives in order to develop and sustain an active social support community of family caregivers on Aloa-aidants.fr.

\section{The Needs of the Family Caregivers of Alzheimers' Patients}

Serious neurodegenerative diseases such as Alzheimer's disease (AD) greatly reduce the patients' autonomy as their cognitive abilities gradually decline. The patients become unable to deal with their own day-to-day requirements as the symptoms worsen, and their relatives have to assist them increasingly with even the simplest operations, such as shopping, bathing, and getting dressed. Patients' relatives find it hard to cope with playing the role of caregiver for which they have not been prepared. As shown by several surveys on French caregivers' situation [1] [8], beyond the 
financial cost of the disease (assistance with housework, adapting the home, etc.), it makes heavy demands on the supporting spouse or relative in terms of time and attention. The ineluctable cognitive decline of $\mathrm{AD}$ patients means that they need an increasing amount of support as their disease progresses.

Caregivers tend to be strongly committed to the support relationship with their ailing relative, whether they are the patient's spouse or child. The assistance they provide takes up a large part of their time and energy and leaves the caregivers little opportunity of escaping and taking care of themselves.

Due to all these worries, caregivers express the need for help, apart from the need for financial assistance, which is felt to be the main response provided by social institutions. They clearly lack a means of expressing their distress and finding a hearing with which discuss their problems in order to obtain information and comfort. The most relevant persons in order to provide this hearing could be other caregivers who are facing similar problems. The only means of this kind available are the support groups run by associations.

Our partner RéGéMA is a healthcare network which focuses on memory disorders such as AD. The main aim of the network is to coordinate the work of the many professionals (neurologists, general practitioners, social workers, psychologists, etc.) involved in the care and support of the these patients. The RéGéMA healthcare network runs monthly support meetings for spouses and children who are caregivers in order to provide them with a space where they can talk about their experience and discuss their problems.

A web-based system appears as a relevant response in order to supplement existing social support devices like face to face support groups. Such system would provide family caregivers with a space available at all times where they can share social support with peers. Online social support can be a way to escape from the burden of caregiving without losing sight of the ailing relative since living the patient alone at home is often difficult. In addition, receiving social support on a daily basis enables people to talk about their problems immediately rather than letting worries accumulate for a long time before they find a hearing. The anonymous communications mediated by the Internet with people living elsewhere might encourage people who are reluctant or unable to participate in face-to-face support groups [12]. Online services of this kind would usefully supplement the services already proposed by medical healthcare networks, as it would improve caregivers' access to information and help them cope with their distressing situation.

\section{Family Caregivers Social Support Practices}

Designing relevant and usable online social support services for family caregivers raise two challenges. First, we need to get a better understanding of current social support practices (computer mediated and face-to-face). And at the same time, we have to understand the specific needs of the family caregivers we are working with in term of social support. We present here the studies that have been carried out on social support practices and caregivers' needs. For both, we highlight several findings that have informed the design of our application. Each study is a complete research on its own and we only focus on some of their results that have been of interest for our purpose. 


\subsection{Understanding Family Caregivers Social Support Practices}

In order to get a better understanding of the current social support practices, two studies have been carried out.

We have conducted a one year and a half participant observation in the support groups ran by RéGéMA. This study gave us an understanding of the situation of RéGéMA family caregivers, the problems they daily encounter and their current social support practices. It also helped us to stay in touch with end-users representatives all along the design process.

The researchers in conversational analysis and psychology involved in this project have studied current computer-mediated social support exchanges taking place on discussion forums on the Internet [13] [14]. They have highlighted the existence of interaction patterns in messages and described a communication contract and sociopsychological factors which underline online social support practices.

These studies have highlighted that self disclosure is important for receiving social support. The analysis of messages posted on social support discussion forums show that users unfold personal and intimate details about their situation and the problem they encounter. Theories on computer mediated communication explain the related psycho-social factors through the need to cope with lack of context [15] and the disinhibitory effect of anonymity [16] [17]. Besides, family caregivers are used to unfold a lot of details, sometime very intimate, about their personal situation when they explain the daily problems they encounter on the occasion of the support groups. Information about their children, the help they receive, even the way their home is arranged may become important details in the stories they want to share with the support groups members.

Another element reported as a key aspect of online social support practices is the importance of reciprocity. The script elaborated on the basis of the online social support exchanges analyzed by our colleagues' researchers in conversational analysis has highlighted this element [7] [13]. At the level of the messages sequence, the common occurrence of an evaluative message at the end of social support exchanges underlines the importance of reciprocity. These evaluative messages through which the support recipient generally thanks the other users for their supportive messages are almost always observed. Their absence may be negatively understood by the members of the discussion thread. Another marker of the expectation of reciprocity is observed at the level of speech acts. The support recipient is often anticipating the support she may receive by thanking other users from her first message. These two elements provide evidence in favor of the presence of a norm of reciprocity underlying the studied online social support discussion forums.

\subsection{Understanding Our Users}

In order to understand the family caregivers' situation and needs, our colleague sociologist has carried out fifteen interviews with family caregivers. This study helped us to gather needs expressed by interviewees and to highlight more latent needs through a better knowledge of their face to face and online social support practices [18] [19]. Eight of the interviewed family caregivers have used online discussions forums in order to help them to cope with their role of caregiver. Some of the interviewees have been recruited on the occasion of RéGéMA support groups. 
A need for information has been generally reported by the interviewees. The healthcare network and the support groups have been mentioned has an important source of information for them. There they can find resources to navigate within the complex medical and administrative environment associated with the disease of their relative, trustworthy information about diseases are provided and also help to plan assistance with housework and in-home care services. The support groups' members share knowledge through the story of their caregiver daily experience and the way they tackle problematic situations (e.g. make bathing or dressing their ailing relative). They explain the different solutions they have tried and what finally works. Experienced caregivers and the support group coordinator suggest solutions to common problems. However, since every situation is unique, a solution for one case may not work for another. The support groups' members explain they appreciate the support they found in the group and the "useful tips" they picked out from each other's experience.

The analysis of the use of online discussion forums by family caregivers [19] underlines that information seeking is their starting point in online social support practices. They pick out and gather information through the stories and questions posted by peers before, if ever, they open their own discussion thread. This is in line with the observation that support in terms of information is central in online social support [14], pure emotional support request are seldom observed and often mixed with information requests [13].

\section{Design Approach}

Integrating the findings brought by these studies coming from different theoretical and methodological perspectives led us to develop an interdisciplinary design framework based on the idea of technical translation [18] [20].

The analysis and results of the studies formerly presented do not constitute a selfevident corpus from which designers can easily derive requirements. In order to make sense of the multi-level features highlighted by social sciences studies, we use the notion of technical translation as a tool to build design requirements from social sciences accounts. Our approach is inspired by the work of Bruno Latour and Michel Callon on the Actor Network Theory (ANT) [21], which provides a framework to describe the dynamic of sociotechnical systems, as are design projects. Through the notion of translation, ANT underlines the dynamic of the multiple voices and interests gathered around an innovation project and the way designed artifacts, as any other actors, take part to project, especially by reifying discourse and acting as representative of multiple intentions.

Our purpose is not to describe these dynamics on the framework of the present project. As designer and stakeholder, we do not feel at ease to rigorously conduct such analysis although we recognize the existence of these phenomena. We are more interested we the last element we have introduced about ANT: the ways artifacts can reify discourses about the activity. To address this perspective, we propose the moderate notion of technical translation through which designers can account for the way functionalities of artifacts translate discourses about the activity and practices proposed by the different stakeholders of a design project. The aim of our translation approach is more to provide a tool for designers rather than a formal methodology to translate 
social sciences and activity inputs directly into system functionalities. The core idea behind our approach is to make open to discussion the detail and purpose of the designed functionalities with non technical stakeholders.

The technical translation approach proposes to begin by selecting elements from the analysis of the activity, the activity features (AF). These AF are formulated by designers in order to reflect their interpretation and understanding of the studies conducted. For instance, we have selected the following AF from the findings formerly presented (section 3):

- Self disclosure is important for receiving social support online.

- Reciprocity is a favorable factor for social support.

- Information seeking is the starting point of family caregivers in online social support practices.

- Informational support plays a central role in social support.

- Caregivers explain they appreciate the "useful tips" they pick out on the occasion of support group sessions.

Designers define functionalities and build mockups according to the selected activity features. Several AF can inspire one or more functionalities. Designers explain the use they envision of their functionalities through scenario.

These materials constitute resources to discuss designers understanding of the activity and the relevance of the proposed functionalities. Through mockups and scenarios, the detailed implementation (user interface and interaction logic) of functionalities is opened to discussion with other project stakeholders [22] [23].

At the end, the technical translations made along the design process constitute a design rationale for the project and a resource for further iterations.

\section{Online Social Support on Aloa-aidants.fr}

We illustrate our design approach by presenting the functionalities - on the basis of the AF formerly introduced - which are offered by Aloa-aidants.fr (fig. 1) in order to support family caregivers.

In order to support self disclosure on our application and provide more contextual information to ease mediated communication, every registered user is invited to present herself through a personal pages (1). They can explain their situation and give news to members with the blog attached to their personal page. Information of interest for family caregivers are highlighted as the city where users live - due to the local context of our application - and the helps users are benefiting (e.g. Autonomy Personal Allowance and support group on the figure). Helps tags can be clicked to find members according to this information. A space dedicated to experience sharing is also available (4) and allow users to share personal stories about the way they cope with the burden of caregiving. Users post their story under an existing topic or create a new one, thus experience of different members on a same subject are gathered. Members can comment and post supportive messages on each others' stories. 


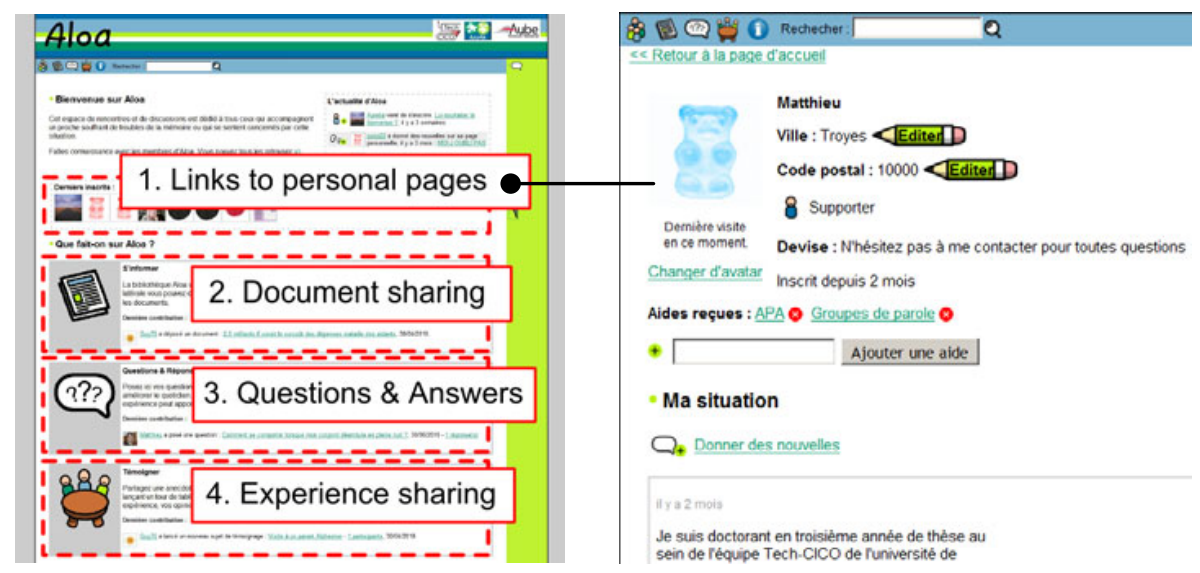

Fig. 1. The front page of Aloa-aidants.fr (left) and a screenshot of a member's personal page (right)

Reciprocity cannot be directly translated into the functionalities of a system. Instead we provide opportunities for users to act with a concern for reciprocity. Users are systematically alerted by email when someone replied to their contributions on Aloa-aidants.fr. Users' contributions that have received few or no messages are emphasized in the front page and at the top of their respective application space. Besides, registered users are invited to greet newcomers.

The Document Sharing space (2) and the Questions and Answers (Q\&A, 3) space are intended to offer informational support to users. A number of documents and websites useful for family caregivers have been uploaded by administrators. Registered users can supplement this space with the document and websites they find useful. Since information seeking is the starting point of family caregivers in online social support practices, all the content but members' personal pages can be viewed by visitors and consulted with the help of our application search engine. In order to highlight content of practical interest for family caregivers like the advices and knowledge exchanged on the occasion of the support groups, every contribution can be marked as a "useful tip" by the mean of a thumb up icon. Thus a collectively build knowledge source is constituted through the "useful tips" picked out by users on the application content. The "useful tips" are gathered under a dedicated section of the Aloa community space and they are always presented in the context of the question, document or user story where they have been mentioned.

\section{Evaluation}

We have made first evaluations of our application according to our twofold aim of designing an application usable by family caregivers and relevant for social support practices. First, an evaluation of the usability of our application has been conducted with RéGéMA family caregivers in order to unfold problems and potential improvements in our design. Second, an evaluation has been conducted with the aim of assessing the relevance of our application for online social support. 
Usability evaluation has consisted of three evaluation sessions that have been carried out with RéGéMA family caregivers. We asked them to complete several tasks on the application and to express their opinion on the credibility and relevance of the use scenario elaborated during the design process. The application is seen as usable by participants according to their comments and their responses to the System Usability Scale (SUS) [24]. Several minor usability problems have been encountered, like problems with the modification of a past contribution or the lack of clarity of the form for sharing documents and websites. We are working to solve these problems for the later version. The remarks made by participants on the use scenarios and the relevance of our application functionalities have been of more interest. Initially, Aloa offers a new member to present her/himself as a family caregiver or a supporter (of the family caregivers cause). One user pointed out that she no more belongs to one or the other group since her ailing relative died several months ago. She suggests we should enable users to present also themselves as former caregiver since a lot of people are concerned with this case. Six months after having deployed Aloa, the experience sharing space encounters little participation. One user reports the fact that she needs to carefully prepare the story she wants to publish on the application. The idea of experience sharing is perceived as a deep and emotional activity. This fact seems to limit the participation on this space. Besides, it shows that the communication situation suggested through the user interface is not neutral. The family caregivers have also reported on the few time they have to spare on the Internet. We observe we have underestimated this aspect by relying a lot on users' participation to generate the content of the application. Preparing more content already available online might bootstrap participation.

The second evaluation was aimed at assessing the relevance of our application for social support practices. It has been carried out with UNISSON, a French family caregivers association aimed at providing support to family caregivers on the Internet. UNISSON was interested to study the opportunity to benefit from an application like Aloa for their purposes. We have provided them with a white-label version of Aloa where they have made extensive tests simulating the way the association brings support to family caregivers on social support discussion forums. At the end of their evaluation, 77 contributions have been posted and 69 user accounts registered. Feedbacks from UNISSON have been positive and they have confirmed their interest in the use of our application for their purpose of supporting family caregivers on the Internet.

\section{Conclusion and Future Work}

In this paper we have exposed the approach we have followed to develop Aloaaidants.fr, an application dedicated to online social support for family caregivers. The findings of social sciences researchers have been really valuable to ground our design theoretically and empirically.

The first version of our online social support application is now online and available for RéGéMA family caregivers since six months. Several messages have been posted by our first users but our aim of supporting an active online community is not currently achieved. As reported by evaluation sessions with family caregivers, more content has to be prepared to motivate users' participation. For instance, we are 
working to gather typical questions asked by new family caregivers at the onset of the disease of their relative. We are also invited to pursue our research on the means to accompany and develop a dynamic online social support community among RéGéMA family caregivers.

Acknowledgements. This research was conducted with the support of Conseil Général de l'Aube in the framework of a strategic research program funded by Troyes University of Technology.

\section{References}

1. IFOP: Etude nationale "Connaître les aidants et leurs attentes" (2008)

2. Barnes, M.K., Duck, S.: Everyday communicative contexts for social support. Communication of social support: Messages, interactions, relationships and community, 175-194 (1994)

3. Pfeil, U., Zaphiris, P.: Patterns of empathy in online communication. In: Proceedings of the SIGCHI Conference on Human Factors in Computing Systems, pp. 919-928. ACM, New York (2007)

4. Dannecker, A., Lechner, U.: Online and Offline Integration in Virtual Communities of Patients - an Empirical Analysis. In: Proceedings of the Third Communities and Technologies Conference, pp. 151-170. Springer, Heidelberg (2007)

5. Preece, J.: Empathic communities: reaching out across the Web. Interactions 5, 32-43 (1998)

6. Lewkowicz, M., Marcoccia, M., Atifi, H., Bénel, A., Gaglio, G., Gauducheau, N., Tixier, M.: Online Social Support: Benefits of an Interdisciplinary Approach for Studying and Designing Cooperative Computer-Mediated Solutions. In: Proceedings of the 8th Conference on the Design of Cooperative Systems, pp. 144-155 (2008)

7. Tixier, M., Lewkowicz, M., Marcoccia, M., Atifi, H., Bénel, A., Gaglio, G., Gauducheau, N.: Practices Analysis and Digital Platform Design: An Interdisciplinary Study of Social Support. In: Proceedings of the 9th Conference on the Design of Cooperative Systems, pp. 309-330. Springer, Heidelberg (2010)

8. PIXEL: Etude PIXEL - L'entourage familial des patients atteints de la maladie d'Alzheimer. Novartis (2000)

9. Cohen, S., Gottlieb, B.H., Underwood, L.G.: Social Relationships and Health. In: Social Support Measurement and Interventions: A Guide for Health and Social Scientists, pp. 3-25. Oxford University Press, New York (2000)

10. Neal, L., Oakley, K., Lindgaard, G., Kaufman, D., Leimeister, J.M., Selker, T.: Online health communities. In: CHI 2007 Extended Abstracts on Human Factors in Computing Systems, pp. 2129-2132. ACM, New York (2007)

11. Josefsson, U.: Patients' online communities experiences of emergent Swedish self-help on the internet. In: Proceedings of the First Communities and Technologies Conference, pp. 369-389. Springer, Heidelberg (2003)

12. Salem, D.A., Bogat, G.A., Reid, C.: Mutual help goes on-line. Journal of Community Psychology 25, 189-207 (1997)

13. Gauducheau, N., Marcoccia, M.: Le soutien social dans les forums de discussion Internet: réalisations interactionnelles et contrats de communication. Psychologie sociale de la communication. De Boeck, Bruxelles 
14. Atifi, H., Gaglio, G.: L'entraide numérique en mots: le cas du forum « aide » des « Marocains d'ailleurs ». In: Actes du congrès de l'AISLF 2009. pp. 336-344 (2009)

15. Klaw, E., Dearmin-Huebsch, P., Humphreys, K.: Communication patterns in an on-line mutual help group for problem drinkers. Journal of Community Psychology 28, 535-546 (2000)

16. Caplan, S.E., Turner, J.S.: Bringing theory to research on computer-mediated comforting communication. Computers in Human Behavior 23, 985-998 (2007)

17. Coulson, N.S.: Receiving social support online: an analysis of a computer-mediated support group for individuals living with irritable bowel syndrome. CyberPsychology \& Behavior 8, 580-584 (2005)

18. Tixier, M., Gaglio, G., Lewkowicz, M.: Translating social support practices into online services for family caregivers. In: Proceedings of the ACM 2009 International Conference on Supporting Group Work, pp. 71-80. ACM, New York (2009)

19. Gaglio, G.: Consommation d'informations sur Internet et modulation de la relation aux médecins - Le cas d'aidantes de malades atteints d'une pathologie lourde. Sociologies Pratiques, 63-74 (2010)

20. Tixier, M.: Aloa: un outil de soutien social en ligne pour les aidants familiaux - Proposition d'une démarche d'analyse et de conception interdisciplinaire. Ph. D. Thesis (2010)

21. Callon, M.: Some elements of a sociology of translation: domestication of the scallops and the fishermen of St Brieuc Bay. Power, action and belief: a new sociology of knowledge? pp. 196-223. Routledge, London (1986)

22. Carroll, J.: Five Reasons for Scenario-Based Design. Interacting with computers 13, 43-69 (2000)

23. Erickson, T.: Notes on Design Practice: Stories and Prototypes as Catalysts for Communication. In: Scenario-Based Design: Envisioning Work and Technology in System Development, pp. 37-58. Wiley \& Sons, New York (1995)

24. Brooke, J.: SUS-A quick and dirty usability scale. Usability Evaluation in Industry, 189194 (1996) 